\title{
PARTICULATE BEHAVIOR IN A CONTROLLED-PROFILE PULVERIZED COAL-FIRED REACTOR: A STUDY OF COUPLED TURBULENT PARTICLE DISPERSION AND THERMAL RADIATION TRANSPORT
}

Quarterly Technical Progress Report

For Period December 15, 1994 to March 14, 1995

\author{
Mardson Queiroz and Brent W. Webb \\ Brigham Young University \\ Provo, UT 84602
}

\section{Prepared for the United States Department of Energy \\ Pittsburgh Energy Technology Center (PETC)}

Under Contract No. DE-FG22-91PC91308

"US/DOE Patent Clearance is not required prior to the publication of this document" 


\section{DISCLAIMER}

This report was prepared as an account of work sponsored by the United States Government. Neither the United States nor the United States Department of Energy, nor any of their employees nor any of their contractors, subcontractors, or their employees, makes any warranty, expressed or implied, or assumes any legal liability or responsibility for the accuracy, completeness, or usefulness of any information, apparatus, product or process disclosed, or represents that its use would infringe privately owned rights. 


\section{DISCLAIMER}

This report was prepared as an account of work sponsored by an agency of the United States Government. Neither the United States Government nor any agency thereof, nor any of their employees, make any warranty, express or implied, or assumes any legal liability or responsibility for the accuracy, completeness, or usefulness of any information, apparatus, product, or process disclosed, or represents that its use would not infringe privately owned rights. Reference herein to any specific commercial product, process, or service by trade name, trademark, manufacturer, or otherwise does not necessarily constitute or imply its endorsement, recommendation, or favoring by the United States Government or any agency thereof. The views and opinions of authors expressed herein do not necessarily state or reflect those of the United States Government or any agency thereof. 


\section{DISCLAIMER}

Portions of this document may be illegible in electronic image products. Images are produced from the best available original document. 


\section{FORWARD}

This report summarizes technical progress during the fourteenth quarter (December 15, 1994 to March 14, 1995) of a three-year study conducted for the Department of Energy (DOE) under contract number DE-FG22-91PC91308. The principal investigators for this work are Dr. Mardson Queiroz and Dr. Brent W. Webb; Dr. Clifford Smith is the technical representative for DOE. 
TABLE OF CONTENTS

PAGE

DISCLAIMER

i

FORWARD

ii

ABSTRACT

iv

1. OBJECTIVES AND SCOPE

1.1 BACKGROUND

1

1.2 OBJECTIVES

1

1.3 TECHNICAL APPROACH

1

2. SUMMARY OF TECHNICAL PROGRESS

2

2.1 PARTICLE DISPERSION MODELLING

2

3. REFERENCES

3

4. APPENDIX

6 


\section{ABSTRACT}

During the fourteenth quarter progress has been made in the area of particle dispersion modeling. 


\section{OBJECTIVES AND SCOPE}

\subsection{BACKGROUND}

Improved understanding of the fundamental processes involved in pulverized-coal combustion is needed to make the energy extraction more efficient and the combustion byproducts environmentally safe. While the characterization of the local particulate behavior (concentration, size, and velocity) is important to the understanding of virtually all processes in a pulverized coal-fired furnace, it influences in a more direct way the turbulent particle dispersion and thermal radiation heat transfer. Yet the local particulate dynamics have gone relatively unaddressed, primarily because of lack of adequate instrumentation to carry out such a study. With recent advances in optical techniques such an effort is now possible. This proposal seeks to characterize the local particulate concentration, velocity, and size distribution in a wellcontrolled, parametrically-varied laboratory-scale reactor using a new laser diagnostic technique. This newly-developed technique is the only one currently available for the investigation of aspherical particles. The particulate data will be collected simultaneously with local gas temperature and wall radiant heat flux distributions.

\subsection{OBJECTIVES}

This report describes recent progress in a fundamental, three-year investigation of the coupled problem of turbulent particle dispersion and thermal radiation transport. The project's objective is to make measurements of particle size, velocity, number density, temperature and wall radiant heat flux in a parametrically-controlled reactor presently existent at Brigham Young University (BYU). Although the study proposed here is primarily designed to provide experimental data not currently available for the evaluation of turbulent particle dispersion and radiation models, comparisons of analytical predictions and the experimental data obtained will be performed, using appropriate submodels integral to comprehensive pulverized-coal combustion codes existent at BYU.

\subsection{TECHNICAL APPROACH}

To accomplish the above objectives, the project is divided in the following tasks:

- Design and fabrication of a modified section for the BYU controlled-profile reactor, which will allow access of several probes to be used in the proposed study.

- Design and fabrication of a two-color pyrometer and cooled probe for local particulate temperature measurement.

- Characterization of the non-reacting turbulent flow field in the reactor using the PCSV-P probe, which will serve as an input during the turbulent particle dispersion submodel validation.

- Literature review dealing with particle dispersion and radiation transport in support of the model validation effort.

- Perform the parametrically-controlled measurements in the controlled-profile reactor.

- Experimental data analysis.

- A comprehensive comparison of experimental data and model predictions.

- Final report. 


\section{SUMMARY OF TECHNICAL PROGRESS}

\subsection{PARTICLE DISPERSION MODELLING}

The Deterministic Separated Flow model used in PCGC-2 accounts for turbulent dispersion by estimating the dispersive component of the particle velocity $\left(u_{i ; p}^{d}\right)$. The particle velocity used in constructing the trajectory is given by:

$$
u_{i ; p}=u_{i ; p}^{c}+u_{i ; p}^{d}
$$

The convective component of the particle velocity $\left(u_{i ; p}^{c}\right)$ is got by replacing the instantaneous gas velocity in particle momentum equation by the time-averaged gas velocity. The dispersive particle velocity needed in the above equation is got from a gradient diffusion approximation (Jurewicz and Stock, 1976; Faeth, 1983). The expression of $u_{i ; p}^{d}$ used in PCGC-2 is of the form (Smoot et al., 1988):

$$
u_{i ; p}^{d}=-\Gamma_{p} \frac{1}{\bar{n}_{p}} \frac{\partial}{\partial x_{i}} \bar{n}_{p}
$$

where $\Gamma_{p}$ is the turbulent particle diffusivity and $\bar{n}_{p}$ is the average particle number density. In order to determine the normalized particle number density gradient appearing in the above equation, Smoot et al. (1988) solved the transport equation for the average particle number density along with the Eulerian gasphase calculations. Thus, the normalized gradient is made available at the time of particle calculation.

Baxter (1989) illustrated that even if all the empirical parameters, such as the turbulent particle diffusivity in Eq. (2), associated with the particle dispersion model in PCGC-2 are accurately known, it lacks a unifying fundamental foundation. He showed that the conceptual interpretation of Eq. (2), which defines the dispersive component of particle velocity for a given particle size originating from a particular starting location, indicates that the particles diffuse down a gradient in their total number density field, regardless of their initial starting location. The dispersive velocity $\left(u_{i, p}^{d}\right)$ appearing in Eq. (2) corresponds to that of a particular particle trajectory, i.e., a particular particle size originating from a particular starting location. Whereas the normalized gradient on the right hand side of Eq. (2) is computed for the total number density for that size irrespective of the starting location.

Furthermore, the assumptions involved in calculating the Eulerian particle number densities and the diffusion coefficients does not guarantee the accurate determination of the total number density gradients for a given particle size. In order to illustrate this a well-behaved experimental data of Bonin (1992) is used to determine the normalized total particle density gradients for a particular size at an axial location in the CPR. Figure 1 gives the number density plot at an axial location of 0.546 meters for a particle size of $30 \mu \mathrm{m}$ for the reacting case Hcase3. This data is considered well-behaved as it can be easily represented by a second order fit as illustrated in the figure. The normalized total number density gradients calculated for the size $30 \mu \mathrm{m}$ using this second order curve fit is compared against the normalized gradients of total particle densities for two different sizes used in simulating Hcase3. The result of this comparison is depicted in Figure 2. Since the simulation did not use $30 \mu \mathrm{m}$ as one of its initial particle size, two different sizes $27.4 \mu \mathrm{m}$ and $32.4 \mu \mathrm{m}$ were used for comparisons. It should be noted that the experimental values of the normalized gradient were divided by $10^{2}$ in order to study the trends within the same plot. It can be seen from these plots that although the general trends match there is about a two order of magnitude difference between the predicted and experimental normalized gradients. Thus, it is quite evident from the above two discussions that the formulation of the dispersive component of the particle velocity is fundamentally very weak. 


\section{REFERENCES}

(1) Baxter, L.L., Turbulent transport of particles, Ph.D. Dissertation, Brigham Young University, Provo, Utah (1989).

(2) Bonin, M.P., Optical measurement of particle size, velocity and number density in pulverized coal flames, Ph.D. Dissertation, Brigham Young University, Provo, Utah, (1992).

(3) Faeth, G.M., Recent advances in modelling particle transport properties and dispersion in turbulent flow, ASME Journal, vol. 2, pp. 517-534 (1983).

(4) Jurewicz, J.T., and Stock, D.E., A Numerical Model For Turbulent Diffusion in Gas-Particle Flows, ASME Paper 76-WA-FE-33 (1976).

(5) Smoot, L.D., Smith P.J., Brewster B.S., and Baxter L.L., Revised User's Manual: Pulverized Coal Gasification or Combustion - 2 Dimensional (87-PCGC-2), Brigham Young University, Provo, Utah (1988).

\section{List of figures}

(1) Number density for $30 \mu \mathrm{m}$ particle at Port $2 \mathrm{a}(x=0.546 \mathrm{~m})$ for a reacting case (Hcase3).

(2) Normalized number density gradient comparison between prediction and experiment for a reacting case (Hcase3). 


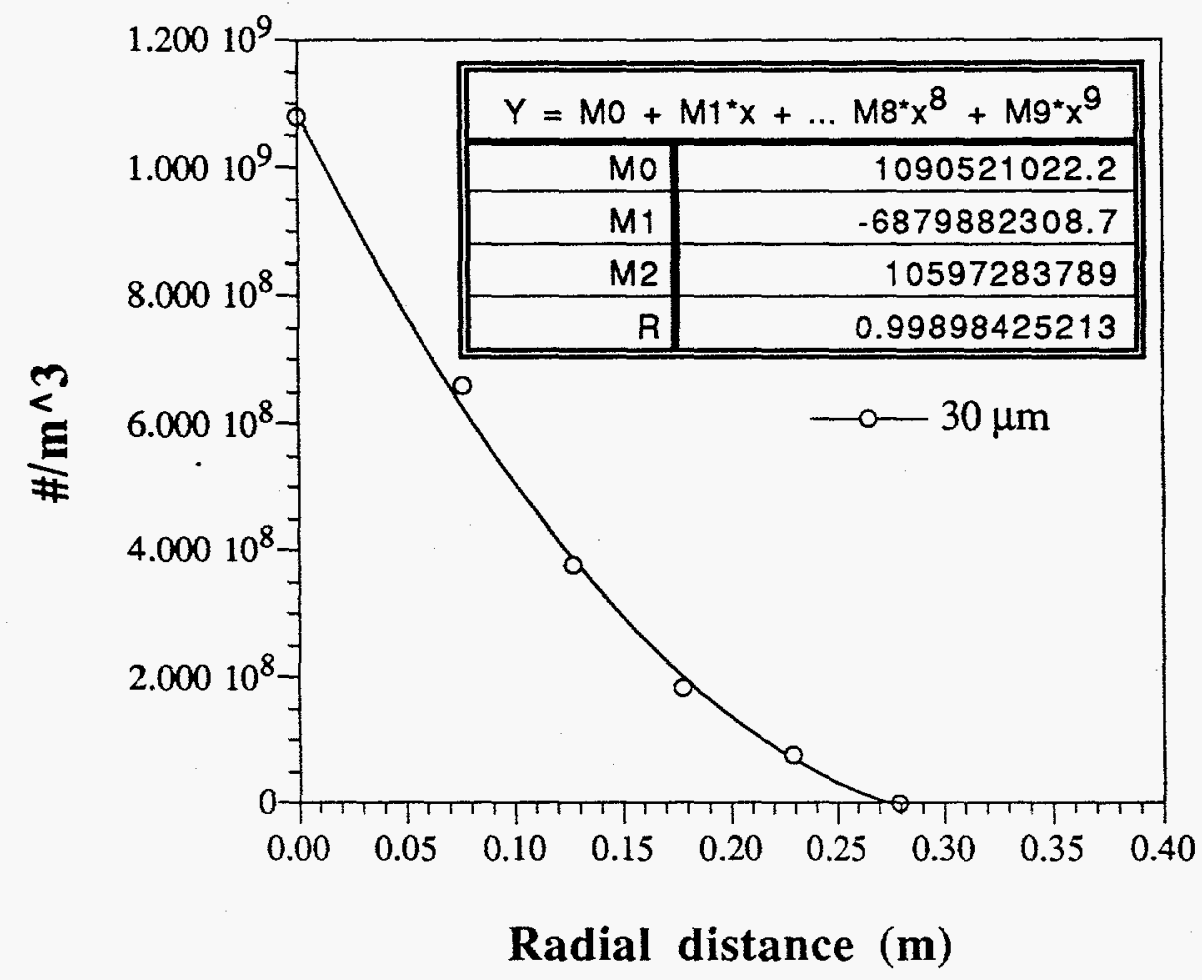

Figure 1. Number density for $30 \mu \mathrm{m}$ particle at Port $2 \mathrm{a}(\mathrm{x}=0.546 \mathrm{~m})$ for a reacting case (Hcase3). 


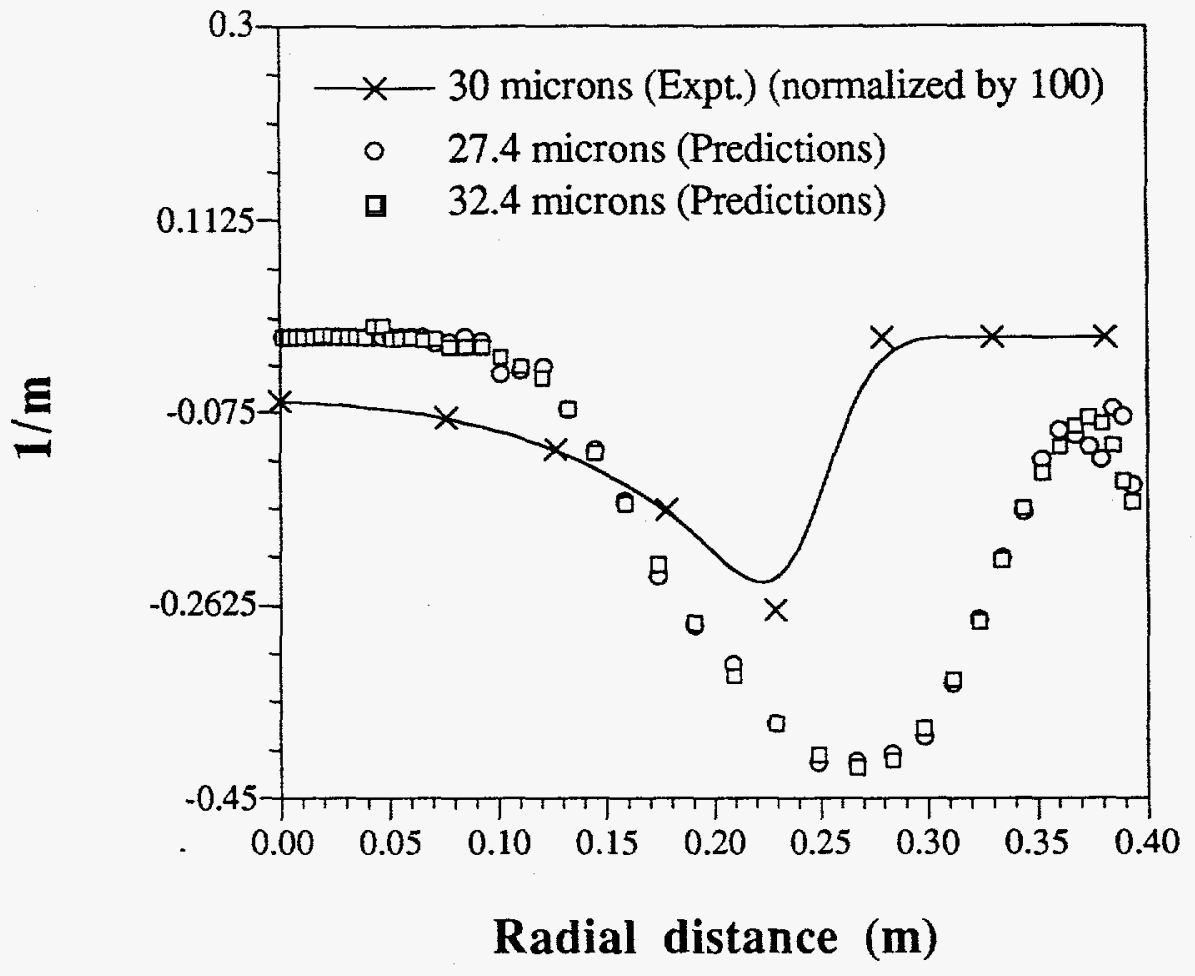

Figure 2. Normalized number density gradient comparison between prediction and experiment for a reacting case (Hcase3). 


\section{APPENDIX \\ REPORT DISTRIBUTION LIST}

Ms. Marilyn Keane

PM-01, MS 922-206

U.S. Department of Energy

Pittsburgh Energy Technology Center

P.O. Box 10940

Pittsburgh, PA 15236

Ms. Rhonda L. Dupree

AD-22, MS 921-118

U.S. Department of Energy

Pittsburgh Energy Technology Center

P.O. Box 10940

Pittsburgh, PA 15236

Office of Technology Transfer

Attn: Kay Downey

Mail Stop 58-M217

U.S. Department of Energy

Pittsburgh Energy Technology Center

P.O. Box 10940

Pittsburgh, PA 15236

U.S. Department of Energy

Attn: Document Control Center

Mail Stop 921-118

P.O. Box 10940

Pittsburgh, PA 15236-0940

Dr. Clifford Smith

U.S. Department of Energy

Pittsburgh Energy Technology Center

P.O. Box 10940

Pittsburgh, PA 15236 